This paper is here reprinted in its entirety because Fig. 5 in the original publication (pp. 2834-2838) and figure 2 in the following paper were interchanged during final assembly for printing.

\title{
Rapid desensitization of glutamate receptors in vertebrate central neurons
}

(excitatory amino acids/synaptogenesis/hippocampus/spinal cord)

\author{
Laurence O. Trussell*, Liu Lin Thio*, Charles F. Zorumski ${ }^{\dagger}$, and Gerald D. Fischbach* \\ Departments of *Anatomy and Neurobiology and of ${ }^{\dagger}$ Psychiatry, Washington University School of Medicine, 660 South Euclid Avenue, St. Louis, MO 63110
}

Contributed by Gerald D. Fischbach, December 4, 1987

\begin{abstract}
We have examined glutamate receptor desensitization in voltage-clamped embryonic chicken spinal cord neurons and postnatal rat hippocampal neurons maintained in culture. Rapid currents that rose in $0.8-3.6 \mathrm{msec}$ were evoked when glutamate was ionophoresed with 0.5 - to 1.0-msec pulses. With prolonged pulses or brief, repetitive pulses, glutamate-evoked currents decayed rapidly in a manner that was independent of holding potential. A similar desensitization occurred following close-range pressure ejection of glutamate. The rapid, desensitizing glutamate current exhibited a linear current-voltage relation and it was not blocked by 2-amino-5-phosphonovalerate, suggesting that it was mediated by $\boldsymbol{N}$-methyl-D-aspartate-insensitive $\left(G_{2}\right)$ receptors. Desensitization of $G_{2}$ receptors may be agonist-dependent: currents evoked by kainate, a selective $\mathbf{G}_{2}$ agonist, did not decay, whereas prior application of glutamate did reduce the size of kainate responses. The appearance of the rapid current depended critically on the position of the ionophoretic pipette. Such glutamate-receptor "hot spots" often corresponded to points of contact with neighboring neurites, which raises the possibility that they are located at synapses.
\end{abstract}

Glutamate is considered to be a "mixed agonist" in that it activates more than one type of receptor. The most common classification of glutamate receptors is based on the relative efficacy of three agonists: $N$-methyl-D-aspartate $(N$-Me-DAsp), kainate, and quisqualate (1-4). In chicken spinal cord neurons, kainate and quisqualate appear to compete for the same site, so we refer to only two broad categories (2): $G_{1}$ receptors are activated by $N$-Me-D-Asp and blocked by 2-amino-5-phosphonovalerate (APV) and $\mathbf{M g}^{2+}$ (the latter in a voltage-dependent manner); $G_{2}$ receptors are activated by kainate and quisqualate. In addition, $G_{1}$, but not $G_{2}$, currents are desensitized following prolonged or repeated application of glutamate (or more selective agonists) over a period of several seconds (5).

It is important to determine whether receptor desensitization occurs on the time scale of synaptic transmission. Our previous studies did not address this issue because the agonists were applied by pressure ejection from pipettes located $25-50 \mu \mathrm{m}$ away from the target neuron $(2,5,6)$. In this situation, the buildup of agonist concentration at the receptor sites is slow compared to the time course of synaptically released transmitter. In addition, such a diffuse application must activate extrasynaptic as well as synaptic receptors.

In this study, we examined rapid desensitization following focal ionophoresis or close-range pressure ejection of glutamate and other agonists. Responses evoked at extremely sensitive sites (hot spots) on the neuronal surface were desensitized rapidly. The desensitizing currents were not

The publication costs of this article were defrayed in part by page charge payment. This article must therefore be hereby marked "advertisement" in accordance with 18 U.S.C. $\$ 1734$ solely to indicate this fact. blocked by APV. These data suggest that $G_{2}$ receptors are, in fact, desensitized but with a time course that is $>2$ orders of magnitude faster than $G_{1}$ receptor desensitization. Some of these results have been presented in abstract form (7).

\section{METHODS}

Neurons from either 6-day embryonic chicken spinal cord or 2- to 7-day postnatal rat hippocampus were dissociated with $0.01 \%$ trypsin or $0.1 \%$ papain, respectively, as described (8, 9). They were grown on glial monolayers in Eagle's minimal essential medium (MEM) supplemented with $10 \%$ (vol/vol) horse serum and either $10 \%$ fetal bovine serum (rat cells) or $5 \%$ chicken embryo extract (chicken cells). After 5 days in vitro, $10 \mu \mathrm{M}$ cytosine arabinoside (1- $\beta$-D-arabinofuranosylcytosine) was added for $\mathbf{4 8} \mathrm{hr}$ to inhibit mitotic cells, the fetal bovine serum was removed, and the chicken embryo extract concentration was reduced to $2 \%$. During electrophysiological experiments, cells were bathed in a solution containing $140 \mathrm{mM} \mathrm{NaCl}, 5 \mathrm{mM} \mathrm{KCl}, 3 \mathrm{mM} \mathrm{CaCl}{ }_{2}, 1 \mathrm{mM} \mathrm{MgCl}_{2}, 1 \mu \mathrm{M}$ tetrodotoxin (except while recording spontaneous synaptic potentials), and $10 \mathrm{mM}$ Hepes buffered to $\mathrm{pH}$ 7.2-7.4. Whole-cell voltage clamp recordings (EPC-7 patch-clamp amplifier; Adams/List) were obtained between 1 and 14 days after plating. Recording electrodes contained $2 \mathrm{mM} \mathrm{NaCl}, 1$ $\mathrm{mM} \mathrm{MgCl}$, and $10 \mathrm{mM}$ Hepes buffered to $\mathrm{pH} 7.2$ plus either $70 \mathrm{mM} \mathrm{Cs}_{2} \mathrm{SO}_{4}$ with $70 \mathrm{mM}$ sucrose or $140 \mathrm{mM} \mathrm{CsCl}$ without sucrose. For high-resolution ionophoretic mapping experiments (see below), cells were viewed under differential interference contrast illumination $(\times 500-1000)$ on a Zeiss ICM 405 equipped with an MTI Newvicon video camera and a Trapix image-analysis system.

Fine-tipped ionophoretic electrodes were filled with 250 $\mathrm{mM}$ glutamate at $\mathrm{pH} 8$. Sibling electrodes, filled with $3 \mathrm{M}$ $\mathrm{KCl}$, measured $60-80 \mathrm{M} \Omega$. We found significant variation in the characteristics of different ionophoretic electrodes in terms of leakage, peak current, clogging, etc. Therefore, in each experiment, the (negative) ejection and (positive) holding (or backing) currents were adjusted as follows: The holding current was set initially to a high value $(>10 \mathrm{nA})$. A site on the neuronal surface was located that responded briskly to a 0.5 - to $1-\mathrm{msec}$ pulse of glutamate. The ionophoretic current was then reduced until the response at this site had a maximal rate of rise and decay. Often the electrode was then repositioned slightly and the ionophoretic current was further refined, as needed. When the settings were optimal, a 2- $\mu \mathrm{m}$ vertical movement of the glutamate pipette resulted in a $>50 \%$ decrease in the evoked current. Optimal responses were usually produced with $100-\mathrm{nA}$ ejection pulses and 5- to 10-nA backing currents. These values are higher than those used with acetylcholine ionophoresis (10),

Abbreviations: $N$-Me-D-Asp, $N$-methyl-D-aspartate; APV, 2-amino5-phosphonovalerate; AMPA, DL- $\alpha$-amino- $\beta$-(3-hydroxy-5-methyl4-isoxazolyl)propionate; $I-V$ relation, current-voltage relation. 
probably because of a relatively low transfer number for glutamate in a $250 \mathrm{mM}$ solution (11).

Glutamate and related agonists $(1 \mathrm{mM})$ were also applied by pressure ejection (55-172 $\mathrm{kPa}$ ) with small-tipped pipettes having resistances (when filled with bath solution) of 10-20 $\mathrm{M} \Omega$. These pipettes were pulled from borosilicate glass on a Kopf patch electrode puller and had a long tapering shank. Positioning of these pipettes within 5-10 $\mu \mathrm{m}$ of the cell body reliably produced transient glutamate responses; higher ejection pressure permitted a greater pipette distance. Lowerresistance, larger-tipped pipettes produced slowly rising responses that did not show rapid desensitization. Pressure application of bath solution alone had no effect.

\section{RESULTS}

Responses to Pressure Ejection and Ionophoresis. Glutamate was applied to neurons by pressure ejection or by ionophoresis. With either method, the shape of the response changed dramatically with small movements of the agonist pipette. Fig. $1 A$ (trace 1 ) shows that a pressure pulse applied to a glutamate pipette located $12 \mu \mathrm{m}$ from a hippocampal neuron produced an inward current with a smooth rising and falling phase. However, after the pipette was repositioned 5 $\mu \mathrm{m}$ from the soma, the slow response was preceded by a fast, transient inward current (trace 2). With $1 \mathrm{mM}$ gluta-
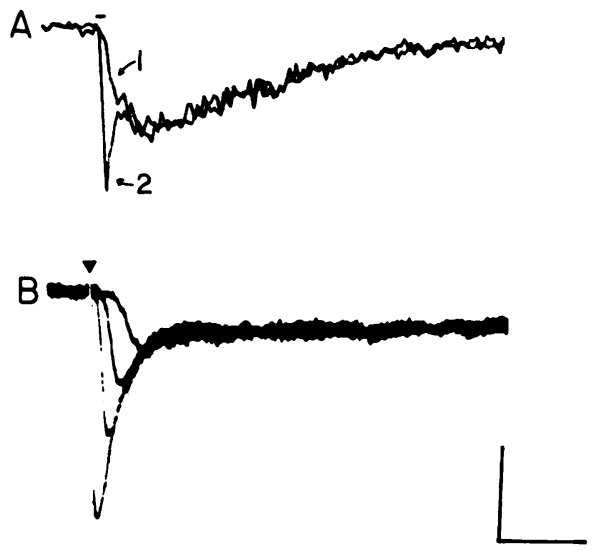

C

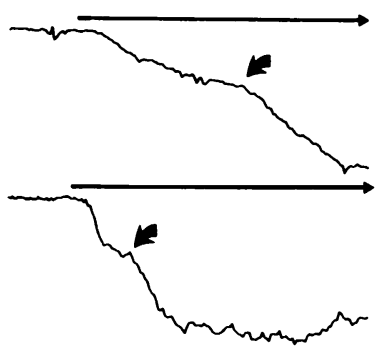

Fig. 1. (A) Pressure application of $1 \mathrm{mM}$ glutamate onto a rat hippocampal neuron $(50 \mathrm{msec}$ at $55 \mathrm{kPa})$. The two superimposed responses were obtained with the agonist pipette positioned at 5 (trace 2) and 12 (trace 1) $\mu \mathrm{m}$ from the soma. (B) Ionophoretic application of glutamate $(2 \mathrm{msec}, 250 \mathrm{nA})$ at a pipette position nearly touching an embryonic chicken spinal cord neuron (the largest response) and at three positions with the pipette pulled increasingly upward in $2-\mu \mathrm{m}$ increments. Note the slow tail in the decay phase. (C) Expanded views of the rising phase of the response of two hippocampal neurons to pressure-ejected $1 \mathrm{mM}$ glutamate. Inflections (curved arrows) during the rise may indicate activation of receptor clusters at different distances from the pipette tip. Horizontal arrows indicate duration of application. Holding potential throughout was $-60 \mathrm{mV}$. [Calibration bars: for $A, 33 \mathrm{pA}, 1 \mathrm{sec}$; for $B, 20 \mathrm{pA}, 40 \mathrm{msec}$; for $C, 100 \mathrm{pA}, 25 \mathrm{msec}$ (top trace) and $50 \mathrm{msec}$ (bottom trace).] mate, the sharp transient averaged $570 \pm 213 \mathrm{pA}$ (mean \pm $\mathrm{SD}, n=12$ hippocampal neurons). When glutamate was applied by ionophoresis, the transient current was even more striking (Fig. 1B). When the ionophoretic pipette dimpled the cell surface, the inward current rose to a peak in as little as $1 \mathrm{msec}$. This fast response was only observed at certain spots on the neuronal surface, suggesting that the glutamate receptors are clustered (see below). Furthermore, close examination of responses evoked by pressure ejection of glutamate revealed one or more inflections on the rising phase (Fig. 1C), consistent with the presence of hot spots located different distances from the tip of the pipette.

Pharmacology and Voltage Dependence. Following a brief ionophoretic pulse, the rapid transient was often followed by a more prolonged inward current that was relatively insensitive to the position of the ionophoretic electrode (Fig. 1B). The early component of the response was due to the activation of $G_{2}$ receptors, while the slow component was generated largely by $G_{1}$ receptors. The slow current, but not the fast transient, was blocked by $0.5 \mathrm{mM}$ APV (Fig. $2 B$ ). Further, the early response exhibited a linear currentvoltage $(I-V)$ relation (Fig. $2 C$, closed circles), whereas the slow-component $I-V$ relation was highly nonlinear (Fig. $2 C$, open circles). Thus, the kinetics of $G_{1}$ and $G_{2}$ currents are quite different following brief application of glutamate. Both components were sensitive to kynurenic acid, a nonselective glutamate receptor antagonist (Fig. $2 A$; ref. 3). At $1.0 \mathrm{mM}$, kynurenate reduced the early and late components by $69 \pm$ $10 \%(n=4)$ and $72 \pm 4 \%(n=3)$, respectively.

Desensitization of the Fast Response. The early glutamate current decayed rapidly even when the application of agonist was maintained. In the example shown in Fig. $3 A$, the response evoked by a $500-\mathrm{msec}$ pressure pulse declined to half amplitude in $110 \mathrm{msec}$. A similar decline in current was observed during prolonged ionophoretic pulses (Fig. $3 B$ ). The decline was also tested by applying two brief ionophoretic pulses separated by various intervals. As shown in Fig. $3 C$, the second response was completely suppressed at an interval of $50 \mathrm{msec}$ and recovered slowly with a half-time of $200 \mathrm{msec}$. Since the second of a closely spaced pair of pulses produced no response at all, it seems likely that the onset of desensitization is at least as fast as the declining phase of currents evoked by the first pulse (half-time $5-15 \mathrm{msec}$ ). Indeed, this period must be considered an overestimate, since the decay of inward current reflects, in part, diffusion to surrounding receptors.

The decline in sensitivity with paired pulses was independent of holding potential over a voltage range of -80 to +50 $\mathrm{mV}$ (Fig. 3D), so the decay was probably due to receptor desensitization rather than to a change in driving force or to a voltage-dependent channel blockade by agonist (12).

Two other $\mathrm{G}_{2}$ agonists, quisqualate and AMPA [DL- $\alpha-$ amino- $\beta$-(3-hydroxy-5-methyl-4-isoxazolyl)propionate; ref. 6], produced fast and rapidly desensitized currents following close-range pressure application (Fig. $4 A$ and $B$ ). On the other hand, responses to $G_{1}$ agonists such as $N$-Me-D-Asp (Fig. 4C), aspartate, and DL-homocysteate did not exhibit rapid desensitization. Previous studies of cultured embryonic chicken neurons indicated that kainate acts at the same site as quisqualate and AMPA (6). However, kainate currents did not show a rapid phase of desensitization during prolonged pressure pulses (Fig. 4D) or repeated brief ionophoretic pulses (Fig. 4E). This does not rule out a common site of action for these $G_{2}$ agonists. As shown in Fig. $4 F$, a prepulse of glutamate markedly reduced a subsequent kainate response, which is consistent with the activation of the same receptor-channel complex. A common site was also supported by ionophoretic mapping studies, in that glutamate hot spots are also sites of high kainate (and quisqualate) sensitivity (data not shown). If kainate, quisqualate, and 

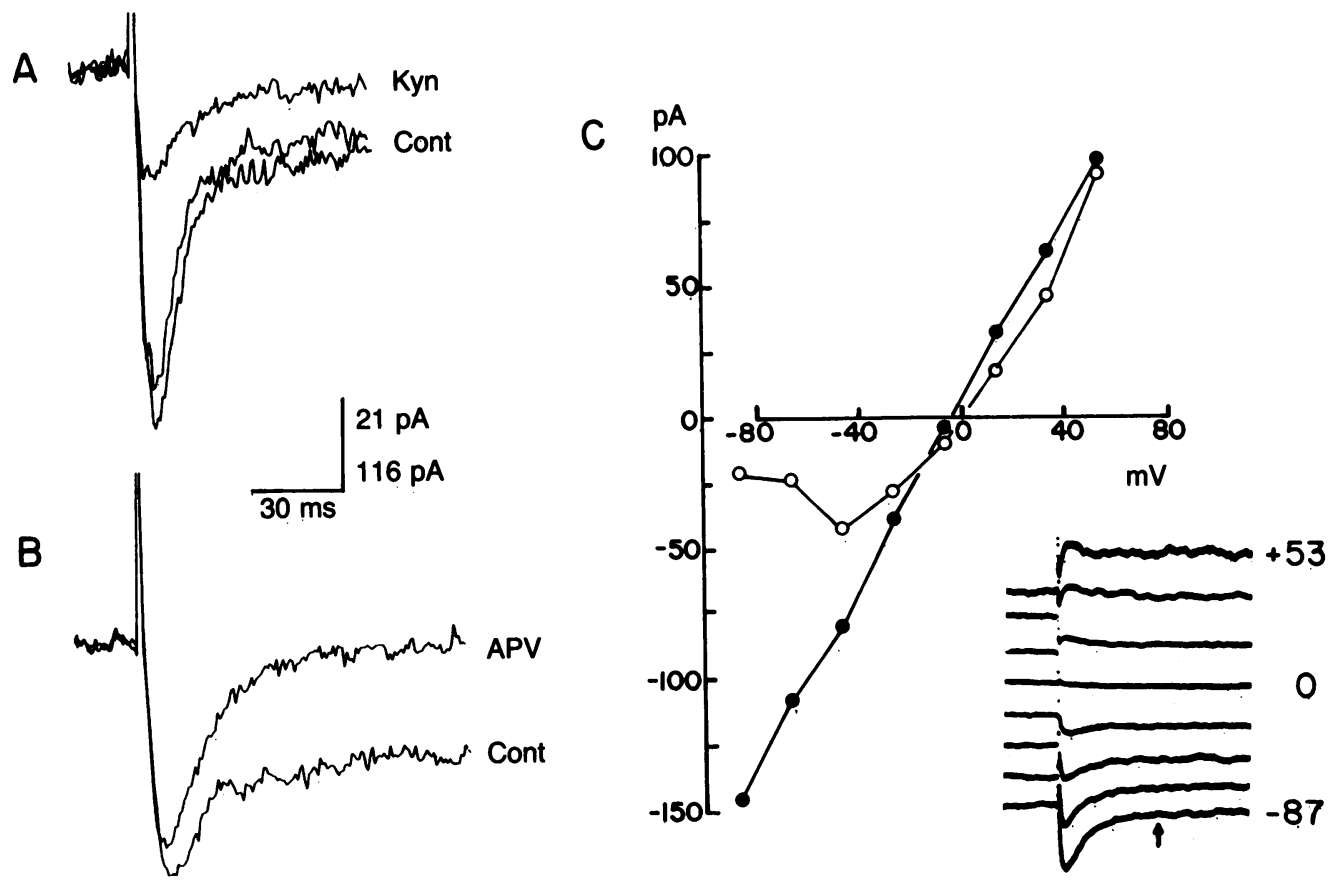

FIG. 2. (A) Effect of $1 \mathrm{mM}$ kynurenic acid (Kyn) on responses of a chicken neuron to a 1-msec ionophoretic pulse of glutamate. Control (Cont) sweeps also show a trace after recovery. The holding potential was $-60 \mathrm{mV}$. (B) Effect of $0.5 \mathrm{mM}$ APV on the response of a hippocampal neuron to a 1-msec pulse of glutamate. The holding potential here was $-30 \mathrm{mV}$ to enhance the contribution of $\mathrm{G}_{1}$ receptor activation. APV and kynurenate were added by pressure ejection. (C) $I-V$ relation for the responses (shown as an Inset) of a hippocampal cell to 1-msec ionophoretic pulses of glutamate. $\bullet, 4 \mathrm{msec}$ after the pulse, corresponding to the peak of the response at $-87 \mathrm{mV} ; 0,50 \mathrm{msec}$ after the pulse. Numbers next to the traces in the Inset indicate the holding potential. The vertical arrow marks 50 msec after the agonist pulse.

glutamate act at the same site, then desensitization must depend on the type of agonist bound. A similar conclusion was reached by Kiskin et al. (13), who studied the amino acid responses of dissociated adult rat hippocampal neurons.

Hot-Spot Topography. As noted above, rapidly desensitized $G_{2}$ currents could be produced only at certain sites on the neuronal surface. Such hot spots were detected on the cell body, but more frequently along major neurites. With the pipette positioned at a hot spot and the ionophoretic currents adjusted for maximal resolution (see Methods), 2to 3- $\mu \mathrm{m}$ movements of the glutamate pipette along a neurite resulted in a $>75 \%$ decrease in inward current. Glutamate hot spots on chicken spinal cord neurons usually coincided with points of crossing by neighboring neurites (Fig. 5). This topography raises the possibility that hot spots are located at or near postsynaptic sites. Indeed, the fastest rise times of focal glutamate currents (i.e., $0.8 \mathrm{msec}$ ) were comparable to the rise times of spontaneously occurring synaptic currents (Fig. 5C). The mean glutamate current rise time $(2.2 \pm 0.9$ msec, mean $\pm \mathrm{SD}, n=11$ ) was somewhat longer than the synaptic current rise time $(0.7 \pm 0.3 \mathrm{msec}, n=149)$. In the same series of measurements, the mean amplitudes of hotspot and synaptic currents were $48 \pm 20$ pA and $36 \pm 25$ pA, respectively. The existence of hot spots, their association with points of contact by other neurons, and the similarity of hot-spot responses to synaptic currents strongly suggest that fast glutamate responses are due to the activation of subsynaptic receptors. Hot spots were also observed on rat
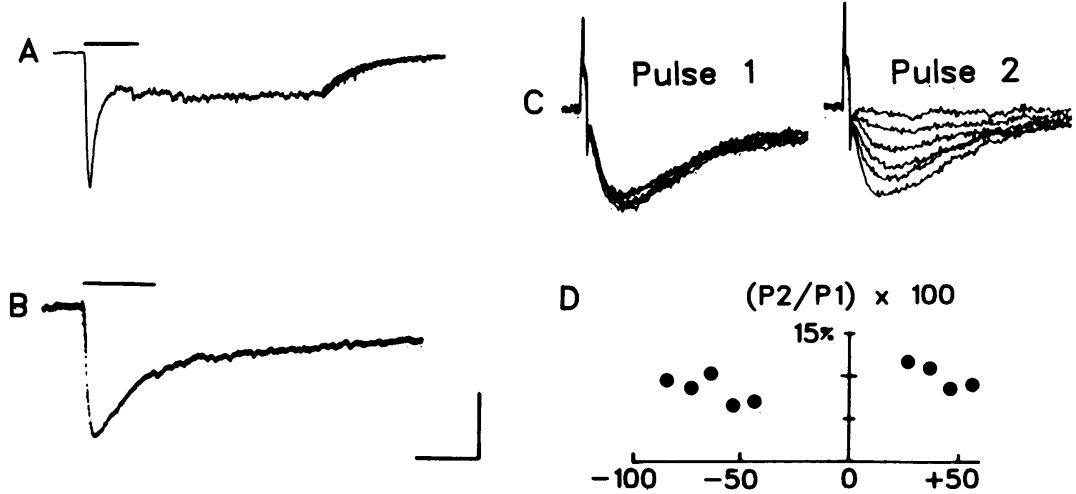

Fig. 3. Desensitization of glutamate responses. (A) Response of a hippocampal neuron to a 500 -msec pressure ejection (bar) of $1 \mathrm{mM}$ glutamate. Note the decline in the response before the end of the application. The apparently exponential termination of the response is due to a change in chart-recorder speed. $(B)$ Desensitization during a 100-msec ionophoretic pulse on a chicken neuron. $(C)$ Desensitization with paired pulse ionophoretic application of glutamate. Six pairs are shown superimposed. The intervals between the first and second pulse that were used are, starting with the smallest to the largest pulse-2 response, 50, 100, 200,300, 400, and 500 msec. (D) Desensitization is not voltage-dependent. The ratio of the second pulse response to the first pulse response (P2/P1) for a pair separated by $75 \mathrm{msec}$ is plotted against holding potential (mV). Holding potential for $A-C$ was $-60 \mathrm{mV}$. (Calibration bars: for $A, 200 \mathrm{pA}, 600 \mathrm{msec}$; for $B, 50 \mathrm{pA}, 90 \mathrm{msec}$; for $C$, 50 pA, 11 msec.) 

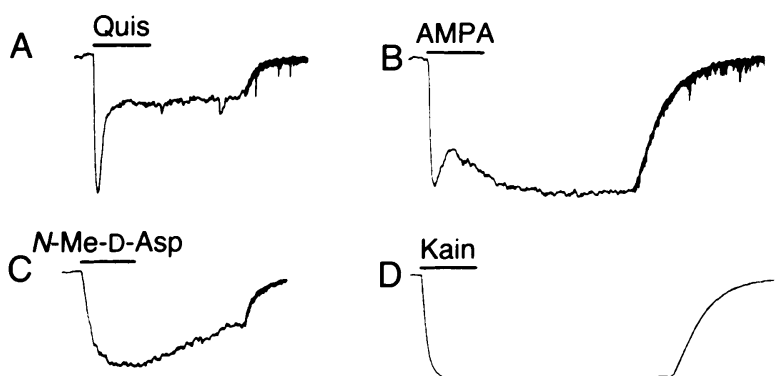

E

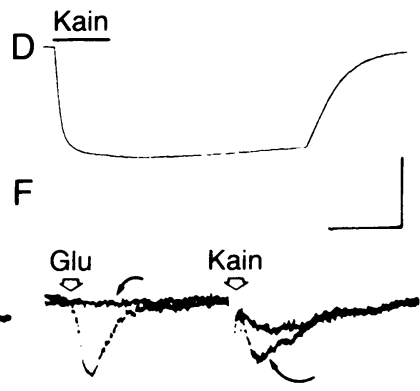

Fig. 4. ( $A-D)$ Response of hippocampal neurons to a 500-msec pressure ejection of $100 \mu \mathrm{M}$ quisqualate $(A), 1 \mathrm{mM}$ AMPA $(B), 1 \mathrm{mM}$ $N$-Me-D-Asp $(C)$, and $1 \mathrm{mM}$ kainate $(D)$. The apparently exponential termination of each response is due to a change in chart-recorder speed. $(E)$ Response of a chicken neuron to a pair of 1-msec ionophoretic pulses of kainate. Note that the second response is slightly larger than the first, presumably due to a transiently less effective backing current. $(F)$ Two superimposed traces showing the effect of glutamate on kainate responses in a chicken neuron. The trace marked by the curved arrows is the response to a single ionophoretic pulse of kainate applied at the arrowhead labeled Kain. The unmarked trace is the response to a prepulse of glutamate at the Glu arrowhead followed by a pulse of kainate at Kain. Even after the glutamate current is gone, the kainate response is clearly reduced. Holding potential throughout was $-60 \mathrm{mV}$. (Calibration bars: for $A$ and $B, 200 \mathrm{pA}, 800 \mathrm{msec}$; for $C, 400 \mathrm{pA}, 800 \mathrm{msec}$; for $D, 800 \mathrm{pA}$, $800 \mathrm{msec}$; and for $E$ and $F, 25 \mathrm{pA}, 24 \mathrm{msec}$.)

hippocampal cells, but the complexity of their axonal arbors (14) prevented a more rigorous analysis.

\section{DISCUSSION}

The rapidly desensitized $G_{2}$ glutamate response described here in chicken and rat neurons has been overlooked in most previous studies. This can be accounted for by differences in the method of glutamate application. We have noted that the leak of glutamate from conventional large-tipped pressureejection pipettes, or from inadequately biased ionophoretic pipettes, is sufficient to abolish the rapid current before a test pulse is applied. Even when the glutamate leak is minimized, the rate of delivery of agonist during the test pulse is critical. We have shown that receptors close to the tip of an ionophoretic pipette begin to be desensitized within $10 \mathrm{msec}$.

Previous studies using 10 - to $100-\mathrm{msec}$ ionophoretic pulses suggested that glutamate receptors were not uniformly distributed over the surface of central nervous system neurons $(15,16)$. Using 0.5 - to 1.0 -msec pulses, we have demonstrated the presence of sharply defined glutamate hot spots. It is not yet clear whether any $G_{2}$ receptors are present in extra-hotspot regions of the membrane. Although peaks of sensitivity were located near points of contact with other neurites, and although the fastest hot-spot responses were similar in time course to synaptic currents, it remains uncertain whether such receptor clusters are truly subsynaptic. Consistent with the idea that hot spots are located at synapses is the observation that, in preparations of isolated chicken motoneurons or of sparsely plated mouse spinal neurons, which would not be expected to receive synaptic contact, the glutamate sensitivity is continuous and graded, with the soma being most sensitive $(15,16)$. Thus, just as motoneurons promote the accumulation of acetylcholine receptors at developing nervemuscle synapses (10), interneurons may trigger the aggregation of glutamate receptors at synaptic sites. It will be important to determine how different neurons promote the accumulation of specific transmitter receptors.

Rapid, brief application of glutamate at hot spots often produced a biphasic current (Fig. $1 B$ and Fig. $2 A$ and $B$ ) that
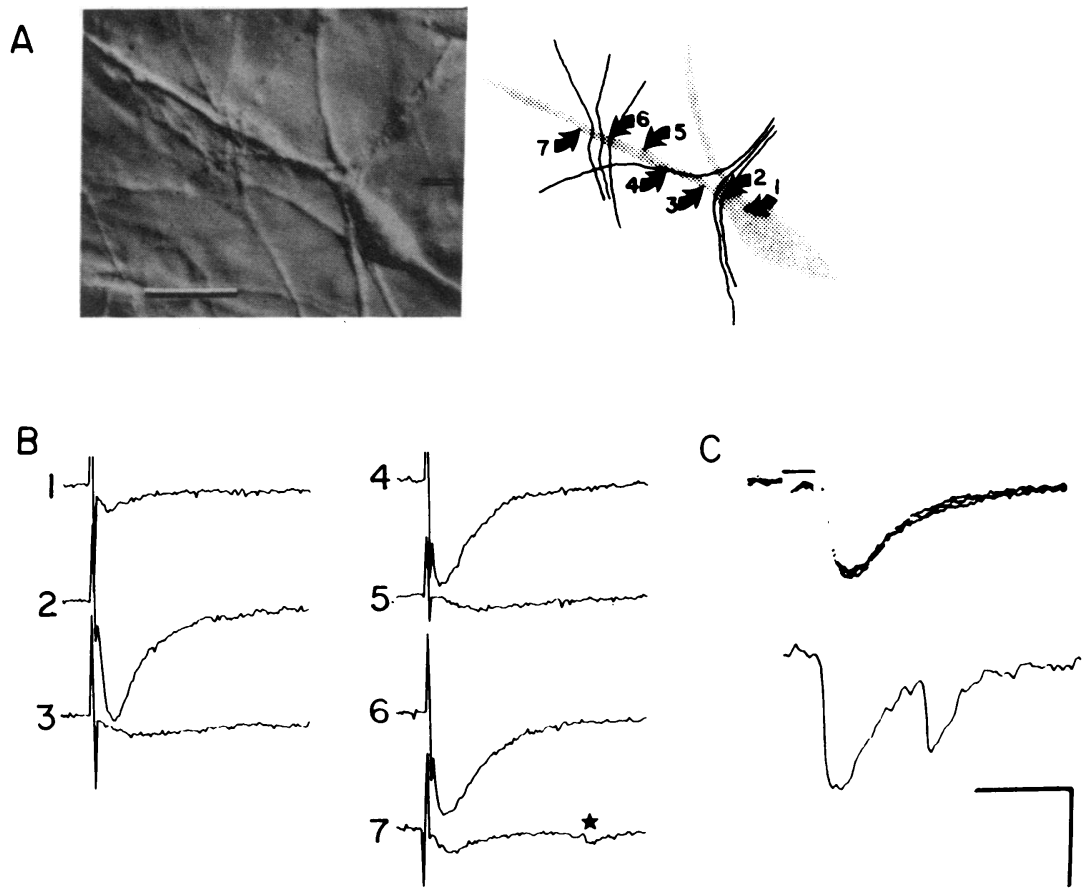

Fig. 5. Localization of glutamate receptors on neurons. $(A)$ Differential interference contrast video image of a chicken spinal neuron in culture for 10 days. (Bar $=24 \mu \mathrm{m}$.) Cartoon version of this image at the right indicates the position of the ionophoretic pipette whose glutamate responses are shown in $B$. The star in trace 7 indicates a small spontaneous synaptic current. $(C)$ Upper trace: a rapid inward current recorded from a chicken neuron in response to a 1-msec, 40-nA pulse with the glutamate pipette acutely positioned at a hot spot on the cell membrane. Lower trace: two spontaneous synaptic currents recorded in a chicken neuron in the absence of tetrodotoxin. Holding potential throughout was $-60 \mathrm{mV}$. (Calibration bars: for $B, 190 \mathrm{pA}, 13 \mathrm{msec}$; for $C, 20 \mathrm{pA}, 2 \mathrm{msec}$.) 
reflected the activation of pharmacologically distinct glutamate receptors. Interestingly, synaptic responses at putatively glutamatergic synapses are characterized by a rapid $G_{2}$-like response followed by a late $G_{1}$-like response $(17,18)$. We have not been able to determine whether $G_{1}$ receptors are clustered, since the slower $G_{1}$ tail appears to be less sensitive to pipette position and rapid $G_{1}$ responses are not observed. If $G_{1}$ receptors have a relatively high affinity for glutamate (19), a response that slowly rises and decays implies that there might be a significant population of extrasynaptic receptors.

Recent studies using rapid-flow techniques have also documented glutamate desensitization $(13,20)$. It would seem likely that in our study and that of Kiskin et al. (13), this process was faster than was determined, due to the time caurse of agonist delivery and to diffusion to surrounding receptors. What is the physiological significance of desensitization? Perhaps rapid desensitization determines the decay rate of each synaptic current or the response to closely spaced repetitive stimuli. Desensitization on a slower time scale $(5,21-24)$ may also affect synaptic function. Extracellular glutamate, which in culture medium is in the micromolar range (15), might tonically inhibit glutamatergic synapses. In addition to mechanisms that regulate extracellular glutamate, desensitization may be influenced by calcium (5) or other intracellular messengers (25). Such hypotheses must be explored by studying the effects of applied glutamate on evoked synaptic responses.

This work was supported by grants from the National Institutes of Health (R01 NS18458, G.D.F.; Physician Scientist Award MH00630, C.F.Z.; T32 GM07200, L.L.T.) and from the Klingenstein Foundation (C.F.Z.), the McKnight Foundation (G.D.F.), and the St. Louis Amyotrophic Lateral Sclerosis Association (L.O.T.).

1. Mayer, M. L. \& Westbrook, G. L. (1987) Prog. Neurobiol. 28, 197-276.

2. O'Brien, R. J. \& Fischbach, G. D. (1986) J. Neurosci. 6, 3275-3283.
3. Watkins, J. C. \& Evans, R. H. (1981) Annu. Rev. Pharmacol. Toxicol. 21, 165-204.

4. Watkins, J. C. \& Olverman, H. J. (1987) Trends Neurosci. 10, 265-272.

5. Zorumski, C. F. \& Fischbach, G. D. (1985) Soc. Neurosci. Abstr. 11, 105.

6. Zorumski, C. F., Yang, J. \& Fischbach, G. D. (1986) Soc. Neurosci. Abstr. $12,56$.

7. Trussell, L. O. \& Fischbach, G. D. (1987) Soc. Neurosci. Abstr. 13, 384.

8. Nakajima, Y., Nakajima, S., Leonard, R. J. \& Yamaguchi, K. (1986) Proc. Natl. Acad. Sci. USA 83, 3022-3026.

9. O'Brien, R. J. \& Fischbach, G. D. (1986) J. Neurosci. 6, 3265-3274.

10. Frank, E. \& Fischbach, G. D. (1979) J. Cell Biol. 83, 143-158.

11. Curtis, D. R. (1964) in Physical Techniques in Biological Research, ed. Nastuk, W. L. (Academic, New York), p. 171.

12. Woodhull, A. M. (1973) J. Gen. Physiol. 61, 687-708.

13. Kiskin, N. I., Khrishtal, O. A. \& Tsendrenko, A. Y. (1986) Neurosci. Lett. 63, 225-230.

14. Banker, G. \& Cowan, W. M. (1979) J. Comp. Neurol. 187, 469-494.

15. O'Brien, R. J. \& Fischbach, G. D. (1986) J. Neurosci. 6, 3290-3296.

16. Ransom, B. R., Bullock, P. N. \& Nelson, P. G. (1977) J. Neurophysiol. 40, 1163-1177.

17. Dale, N. \& Roberts, A. (1985) J. Physiol. (London) 363, 35-59.

18. Collingridge, G. L. \& Bliss, T. V. P. (1987) Trends Neurosci. 10, 288-293.

19. Olverman, H. J., Jones, A. W. \& Watkins, J. C. (1984) Nature (London) 307, 460-462.

20. Franke, C., Hatt, H. \& Dudel, J. (1987) Neurosci. Lett. 77, 199-204.

21. Vlachova, V., Vyklicky, L., Vyklicky, L. \& Vyskocil, F. (1987) J. Physiol. (London) 386, 425-438.

22. Mayer, M. L. \& Westbrook, G. L. (1985) J. Physiol. (London) 361, 65-90.

23. Takeuchi, A. \& Takeuchi, N. (1964) J. Physiol. (London) 170, 296-317.

24. Ishida, A. T. \& Neyton, J. (1985) Proc. Natl. Acad. Sci. USA 82, 1837-1841.

25. Huganir, R. L., Delcour, A. H., Greengard, P. \& Hess, G. P. (1986) Nature (London) 321, 774-776. 